\title{
Interstitial fluid flow in cancer: implications for disease progression and treatment
}

\author{
This article was published in the following Dove Press journal: \\ Cancer Management and Research \\ 19 August 2014 \\ Number of times this article has been viewed
}

\author{
Jennifer M Munson' \\ Adrian C Shieh² \\ 'Department of Biomedical \\ Engineering, University of Virginia, \\ Charlottesville, VA, ${ }^{2}$ School of \\ Biomedical Engineering, Science and \\ Health Systems, Drexel University, \\ Philadelphia, PA, USA
}

Correspondence: Jennifer M Munson Department of Biomedical Engineering, University of Virginia, PO Box 800759, Charlottesville, VA 22908, USA

Tel +l 4349248080

Email munson@virginia.edu

\begin{abstract}
As cancer progresses, a dynamic microenvironment develops that creates and responds to cellular and biophysical cues. Increased intratumoral pressure and corresponding increases in interstitial flow from the tumor bulk to the healthy stroma is an observational hallmark of progressing cancers. Until recently, the role of interstitial flow was thought to be mostly passive in the transport and dissemination of cancer cells to metastatic sites. With research spanning the past decade, we have seen that interstitial flow has a promigratory effect on cancer cell invasion in multiple cancer types. This invasion is one mechanism by which cancers can resist therapeutics and recur, but the role of interstitial flow in cancer therapy is limited to the understanding of transport of therapeutics. Here we outline the current understanding of the role of interstitial flow in cancer and the tumor microenvironment through cancer progression and therapy. We also discuss the current role of fluid flow in the treatment of cancer, including drug transport and therapeutic strategies. By stating the current understanding of interstitial flow in cancer progression, we can begin exploring its role in therapeutic failure and treatment resistance.
\end{abstract}

Keywords: tumor microenvironment, interstitial flow, therapeutics, invasion

\section{Tumor microenvironment}

Although cancer arises from transformation of single cells, once a tumor initiates, the surrounding tissue is altered to promote cancer survival and growth. This tumor microenvironment includes all of the cells and tissue components aside from the cancer. These components, including cells and extracellular matrix proteins, and growth factors, can vary based on the tissue stroma in which the cancer forms. That being said, there are parallels amongst the different solid tumors and their associated microenvironments that may impede the efficacy of cancer therapies. These include biophysical and biochemical barriers. Biochemically, cancer and cancer-associated cells secrete a number of cytokines to sustain their growth and development that can interfere with the success of antiproliferative therapeutics, including antimitotics, DNA intercalating agents, and receptor tyrosine kinase inhibitors. ${ }^{1,2}$ Biologically, cancer-associated cells, such as fibroblasts and immune cells, can affect therapeutic resistance in ways that are still being elucidated. ${ }^{1}$ Biophysical forces such as stromal stiffening, ${ }^{3}$ interstitial pressure, ${ }^{4}$ and fluid flow ${ }^{5}$ have a number of effects on the ability of therapy to both reach the tumor microenvironment and induce the desired response in cancer cells.

\section{Biophysical microenvironment}

The biophysical microenvironment of the tumor has been best studied in breast cancer, the second most frequently occurring cancer next to skin cancer. Here we know that 
the tumor microenvironment becomes mechanically stiff due to accumulation and reorganization of extracellular matrix proteins and activation of stromal fibroblasts. ${ }^{3}$ These changes in tissue reorganization have broad-reaching effects on cancer cells. ${ }^{6}$ Stiffening of tissue has been correlated with a poor prognosis and softening of tissue reduces metastasis and disease progression in mouse models of breast carcinoma. ${ }^{7}$ Not only has this effect been seen in breast cancer, but has been used as a diagnostic and surgical tool in many other cancers, including those of the brain, skin, liver, and lung, where the mechanical stiffness of the native tissue can increase up to 100 times that in the healthy state..$^{8,9}$

The tissue in which a cancer develops is a confined space with limited inlets and outlets for cells, fluids, and waste. As the cancer grows, it pushes on the surrounding environment until it eventually invades the tissue. This process results in a buildup of pressure from the inside out and can lead to a vast pressure differential between the tumor and the tissue in which it resides. This increased interstitial pressure has been studied for over 30 years, with documentation in human clinical samples and mouse models of cancer. ${ }^{10-12}$ Heldin et al recently identified this high pressure as a crucial factor in therapeutic failure for a number of reasons, and Ariffin et al have nicely reviewed the implications of and strategies to reduce interstitial pressure in cancer. ${ }^{4,13}$ The high pressure of the tumor next to the normal pressure of healthy tissue leads to pressure gradients resulting in the development of fluid flow through the tumor stroma. ${ }^{14}$ This increased fluid flow was first documented in murine mammary tumors, ${ }^{15}$ and has since been documented using fluorescence recovery after photobleaching in neoplastic tissue in rabbit ears and via magnetic resonance imaging (MRI) in multiple models of cancer. ${ }^{16,17}$ Table 1 outlines the studies that have, to date, quantified interstitial flow (IF) in tumors, along with the methodology used and the measured flow velocities.
One observation is that there are relatively few experimental measurements of IF in tumors, and even fewer in normal tissues. With the measurements that have been made, the velocities in animal models are an order of magnitude or more lower than the measurements made in human patients with cervical carcinoma. Some of these differences may arise from the particular animal models used, such as xenografts implanted ectopically into nude mice ${ }^{18,19}$ or cells injected into a rabbit ear chamber. ${ }^{16}$ These tumors and their surrounding microenvironments may be substantially different from spontaneous human tumors, particularly in those cases where the immune system is compromised and cells are implanted in sites other than their tissue of origin. Nonetheless, some of these experimental measurements of interstitial pressure and flow have been corroborated by a variety of mathematical models of the tumor fluid environment. These models predict maximum IF velocities in the range of $0.01-1 \mu \mathrm{m}$ per second. One common theme shared by these mathematical models and the aforementioned experimental measurements is that peak velocities occur at the edge of the tumor, where the pressure gradient is steepest. ${ }^{20-23}$ However, each of these mathematical models is limited by their specific assumptions regarding tumor geometry and hydraulic properties of the tumor and the surrounding stroma, which strongly affect predicted IF velocities. In most cases, the significant heterogeneity of the tumor and its microenvironment are not captured in any meaningful way. Based on these mathematical models, as well as the few experimental measurements of IF that have been made, it is typically assumed that IF velocities range from 0.1 to $10 \mu \mathrm{m}$ per second; however, it is possible that these results are biased by the use of models of human cancer, rather than naturally occurring human cancers. Thus, while these studies suggest that IF is altered in the tumor microenvironment, they also emphasize the dearth of information available regarding IF in tumors and

Table I Measurements of interstitial flow in vivo for different cancer types

\begin{tabular}{|c|c|c|c|}
\hline Cancer and model & Method & Interstitial flow velocity $(\mu \mathrm{m} / \mathrm{sec})$ & Reference \\
\hline $\begin{array}{l}\text { MTW9 and Walker } 256 \text { mammary } \\
\text { carcinomas in rats }\end{array}$ & $\begin{array}{l}\text { Implanted micropore diffusion } \\
\text { chamber }\end{array}$ & $\begin{array}{l}4-5 \text { times greater interstitial drainage } \\
\text { in tumors }\end{array}$ & Butler et al ${ }^{15}$ \\
\hline $\begin{array}{l}\text { Rabbit ear chamber with normal and VX2 } \\
\text { carcinoma neoplastic tissue }\end{array}$ & $\begin{array}{l}\text { Fluorescence recovery after } \\
\text { photobleaching }\end{array}$ & $\begin{array}{l}\text { Normal: } 0.59 \pm 0.16 \\
\text { Neoplastic: } 0.55 \pm 0.16\end{array}$ & Chary and Jain ${ }^{16}$ \\
\hline $\begin{array}{l}\text { Inducible VEGF } 165 \text {-expressing C6 tumors } \\
\text { in mice }\end{array}$ & Dynamic contrast-enhanced MRI & $\begin{array}{l}\text { No VEGF I65: } \sim 0 \\
\text { VEGF I65: } 0.1-0.5\end{array}$ & Dafni et al ${ }^{19}$ \\
\hline $\begin{array}{l}\text { TS- } 415 \text { human cervical carcinoma } \\
\text { xenografts in mice }\end{array}$ & Dynamic contrast-enhanced MRI & $2-8$ & Hompland et al ${ }^{18}$ \\
\hline U-25 human melanoma xenografts in mice & & $\mathrm{I}-8$ & \\
\hline Locally advanced squamous cell carcinoma & & Nonmetastatic: $5-25$ & \\
\hline of the uterine cervix (human patients) & & Metastatic: 10-55 & \\
\hline
\end{tabular}

Abbreviations: MRI, magnetic resonance imaging; VEGF, vascular endothelial growth factor. 
the effects that this flow can have on cancer. This review focuses on the current data elucidating the role of IF on cancer progression and therapeutic approaches, ending with an outlook of the unstudied aspects of IF in cancer and how it might be contributing to treatment resistance.

\section{Origins of interstitial flow in cancer}

Interstitial fluid refers to the fluid that is found in the stroma of tissue. In healthy tissue, this fluid results from an influx of plasma from the blood vasculature as nutrients and oxygen are transported into the stromal space and from cells as they undergo metabolism. ${ }^{24}$ The majority of the fluid that leaks from the blood capillaries is reabsorbed by the post-capillary venules, but a fraction of the fluid filters through the interstitium and drains through the lymphatic vasculature downstream, eventually emptying into the venous bloodstream. Under healthy conditions, this system prevents buildup of fluid in the interstitial space. In cancer, the amount of fluid is greatly increased and poorly drained, resulting in an increase of interstitial pressure in the tumor that leads to a steep gradient of pressure between the tumor and the surrounding healthy tissue. ${ }^{10}$ This gradient results in higher interstitial fluid flow into the healthy tissue and draining lymphatics.

In cancer, there are a host of irregularities in the vasculature that contribute to the malfunction of this perfectly coordinated system and lead to increased flow rates through the tissue. Angiogenesis and lymphatic co-option are correlated with poor tumor prognosis and progression of cancer, and are the primary contributors to the changes in fluid flow and interstitial pressure in the tumor microenvironment. ${ }^{25}$

Angiogenesis is the generation of new blood vessels from existing vessels and occurs in and around the periphery of the tumor. Tumor cells secrete a number of factors to induce angiogenesis, most notable of which is vascular endothelial growth factor. ${ }^{26}$ Vessels that develop in the tumor microenvironment are largely irregular. They are marked by large gaps in the endothelial cell layer, reduced pericyte and smooth muscle coverage, and oddly sized and shaped structures. ${ }^{27}$ The increased vessel number together with increased hydraulic conductivity, or the relative ease with which fluid moves across the vessel wall, results in an irregular and increased influx of fluid into the tumor stroma. ${ }^{17}$ Modeling approaches for IF have shown that the irregularities in tumor vasculature are tightly linked to changes in interstitial pressure and fluid flux. ${ }^{28,29}$

Unlike angiogenesis, which is seen in a majority of solid tumors, intratumoral lymphangiogenesis, or the growth of new lymphatic vessels, is rarely seen. ${ }^{30}$ Tumors rely on lymphatic vessels already present in the co-opted tissue to drain the fluid from the cancer. These vessels enlarge, become more permeable, and have increased drainage capacity as the cancer progresses. ${ }^{31}$ In some cancers, there are increases in lymphatic vessels peritumorally or in the draining lymph node that can contribute to altered drainage in the peripheral tissue. However, these new vessels do not effectively balance the increase in fluid from the blood vessels, resulting in an overall pressure increase in the tumor bulk with a steep decrease in pressure at the periphery.

This increased pressure is due not only to the fluid that cannot properly drain out of the interstitium, but also to a number of other physiological changes in the tissue microenvironment. This includes both the increase in cell number and the increase in extracellular matrix deposition in the stroma.

\section{Cell growth}

The best known hallmark of cancer is the unchecked growth and proliferation of the transformed cancer cells. ${ }^{32}$ As cancer cells expand in a confined environment, they press on the surrounding stroma and extracellular matrix. This leads to an increase in the elastic stress on this tissue, and since the area cannot expand, translates to an increase in the intratumoral pressure. ${ }^{33}$ This pressure increase has been documented in numerous cancers and can be 10-100-fold greater than that of the healthy surrounding tissue..$^{10,12,34,35}$ This high pressure differential drives fluid flow at the periphery of the tumor mass corresponding to the invasive front. Interstitial fluid flows from the tumor toward the healthy tissue and eventually empties into the tissue lymphatics. ${ }^{33}$ Aside from the expansion of the cells, the increase in metabolic activity of cancer cells yields an increase in extracellular secretion and accumulation of biomolecules and electrolytes that enhance the overall mass of the tumor. Stromal cells and infiltrating immune cells respond to the cytokines secreted in the tumor microenvironment, contributing to the cell-associated pressure and expansion of the tissue. ${ }^{36}$

\section{Extracellular matrix}

Cancer and stromal cells in the tumor microenvironment alter the extracellular matrix components as they grow and invade the healthy tissue. This includes irregular deposition and degradation of protein components, such as fibronectin and collagen, and glycosaminoglycans such as hyaluronan. ${ }^{37}$ Stromal cells in the activated microenvironment alter the architectural and physical properties of the extracellular matrix, crosslinking, and aligning fibrils. These changes 
contribute to the characteristic stiffening of the tumor that is well documented as a prognostic and diagnostic indicator in multiple solid cancers. ${ }^{3}$ Due to these changes in the extracellular matrix structure, and in spite of the enhanced deposition of extracellular matrix proteins, the hydraulic conductivity increases in the tumor towards healthy tissue. ${ }^{38}$ These changes in extracellular matrix contribute to the enhanced invasion and metastasis that correlate with heterogeneous fluid flow pathways through the tissue..$^{21,39}$

\section{Interstitial flow and progression of cancer}

Fluid flows from solid cancers have been documented in animal models and clinical settings. The high interstitial pressures result in efflux of fluid from the tumor into the surrounding tissue, resulting in increased swelling of the draining tissues in lymph nodes or ventricular spaces of the central nervous system. ${ }^{40,41}$ Understanding the role of IF in the progression of cancer is expanding. Its incorporation and measurement in vitro and in vivo is important to properly developing and implementing new therapeutic strategies.

\section{Effects on cancer cells}

The direct effects of IF on cancer cells are the best studied phenomena thus far. Using two-dimensional and threedimensional tissue culture models with controlled fluid flow and pressure differentials has allowed examination of a number of malignant behaviors. The development of microfluidic devices and cell analysis strategies has been integral to the understanding of the behavior of cells in the microenvironment and has recently been reviewed by $\mathrm{Wu}$ and Swartz. ${ }^{42}$ Recent experiments examining multiple models of cancer and the response to interstitial or low shear flows are summarized in Table 2.

\section{Invasion}

Cancer cell invasion and migration has been the best studied of the phenomena related to cancer progression. The role of flow appears to be primarily promigratory; however, other microenvironmental factors can influence how the cell detects and responds to this stimulus. ${ }^{43}$ Breast cancer cells exposed to IF in a three-dimensional collagen microenvironment show increased migration both in three-dimensional tissue culture inserts and in specially designed three-dimensional flow chambers. ${ }^{44,45}$ Similarly, glioma cells have been shown to increase migration in the presence of IF in multiple ways. First, glioma cells exposed to continuous flow in the absence of chemokine gradients were shown to have enhanced cell motility and directional cell migration in hyaluronan matrices. ${ }^{46}$ Second, glioma cells embedded in collagen gels showed enhanced chemotaxis after exposure to IF. ${ }^{47}$ The enhanced motility seems to occur via several proposed mechanisms. Flow can trigger increased kinesis of cells via activation of surface receptors, such as the chemokine receptor CXCR4. It has also been proposed that small pericellular gradients can form around cells dispersed in a matrix (like what is seen at the leading invasive edge of a solid tumor) to yield a chemokine gradient across the body of the cell. This gradient can induce directional migration through a mechanism termed "autologous chemotaxis". ${ }^{48}$ Studies using higher concentrations of cells and exposing them to pressure gradients have shown changes in cell migration, but no directional migration. ${ }^{49,50}$ This could indicate that the chemokine-induced changes may only be relevant at the leading edges of tumors, where the protein distribution is more heterogeneous and fluid flows are more marked.

In vivo, IF in tumors has been measured in human and animal cancers. This flow rate can also be estimated based on an observed drainage rate of dye from the tissue into the lymph or cerebrospinal fluid. ${ }^{51,52}$ In melanoma, it has been noted that fluid transport in the interstitium and to the draining lymph nodes actually increases prior to lymph node metastasis of cancer cells. ${ }^{53}$ In breast cancer, routes of extravascular fluid flux correspond to invasive fronts in mouse models of carcinoma, ${ }^{51}$ and brain cancer invasion tightly corresponds to pathways of fluid drainage. ${ }^{54}$ Elevated IF has also been correlated with lymph node metastasis in patients with cervical carcinoma, as well as xenograft models of cervical carcinoma and melanoma. ${ }^{18}$ These results indicate the possibility of fluid flow as a prognostic indicator of eventual invasion and metastasis.

\section{Proliferation and growth}

Aside from invasion, cancer proliferation and growth are major causative factors in the progression of disease. Low shear flows and IFs have been implicated in inducing proliferation in many normal cells including osteoblasts, ${ }^{55}$ adipose-derived stem cells, ${ }^{56}$ and endothelial cells. In cancer, early evidence suggests that IF has effects on cellular proliferation and differentiation. In multiple cancer cell lines, application of shear stress resulted in $\mathrm{G}_{2} / \mathrm{M}$ arrest, indicative of inhibition of differentiation of cancer cells. ${ }^{57}$ This is the first evidence of fluid flows affecting the cancer cell cycle. Interstitial pressure changes are responsible for altering the invasive and proliferative phenotype of cancer cells towards malignancy. ${ }^{58}$ These data indicate that IF may have an effect on proliferation and growth, which 
Table 2 In vitro studies examining the effects of shear of interstitial flow on cancer cells

\begin{tabular}{|c|c|c|c|c|}
\hline Cancer model & Description of flow & Experimental setup & Finding & Reference \\
\hline $\begin{array}{l}\text { MCF7 and ZR75-I breast } \\
\text { carcinoma; MDAMB435S } \\
\text { melanoma (human) }\end{array}$ & $\begin{array}{l}\text { Interstitial, continuous } \\
(0.2 \mu \mathrm{m} / \mathrm{sec})\end{array}$ & $\begin{array}{l}\text { Tumor cells in collagen-matrigel } \\
\text { matrices. Tissue culture inserts and } \\
\text { radial flow chambers. Lymphatic } \\
\text { endothelial cells incorporated as a } \\
\text { downstream monolayer. }\end{array}$ & $\begin{array}{l}\text { Invasion was increased with } \\
\text { lymphatics or flow and } \\
\text { exponentially increased with } \\
\text { both. This could be blocked by } \\
\text { blocking CCR7. }\end{array}$ & Shields et $\mathrm{al}^{44}$ \\
\hline $\begin{array}{l}\text { MG63 and Saos } 2 \\
\text { osteosarcoma; SCC25 } \\
\text { oral squamous carcinoma; } \\
\text { SWI } 353 \text { chondrosarcoma } \\
\text { (human) }\end{array}$ & Shear flow $\left(12\right.$ dyne $\left./ \mathrm{cm}^{2}\right)$ & $\begin{array}{l}\text { Monolayers of cells exposed to } \\
\text { shear stress for } 12-48 \text { hours. }\end{array}$ & $\begin{array}{l}\text { Shear stress induced } G_{2} / M \text { arrest } \\
\text { and static conditions induced } \\
G_{0} / G_{1} \text { arrest. Effect is mediated } \\
\text { by } \alpha_{v} \beta_{3} \text { and } \beta_{1} \text { integrins. }\end{array}$ & Chang et $\mathrm{al}^{57}$ \\
\hline $\begin{array}{l}\text { MDAMB435S human } \\
\text { melanoma with human } \\
\text { dermal fibroblasts }\end{array}$ & $\begin{array}{l}\text { Interstitial, continuous } \\
(0.5 \mu \mathrm{m} / \mathrm{sec})\end{array}$ & $\begin{array}{l}\text { Cells cocultured in a collagen } \\
\text { matrix in tissue culture inserts. }\end{array}$ & $\begin{array}{l}\text { Synergistic increase in cancer } \\
\text { cell invasion with addition of } \\
\text { flow and fibroblasts. Fibroblasts } \\
\text { migrate in a TGF- } \beta \text {-dependent } \\
\text { and collagenase-dependent } \\
\text { fashion. }\end{array}$ & Shieh et $\mathrm{al}^{70}$ \\
\hline $\begin{array}{l}\text { U87 and U25I human } \\
\text { glioma; CNS-I rat glioma }\end{array}$ & $\begin{array}{l}\text { Interstitial, noncontinuous } \\
(0.8-3 \mu \mathrm{m} / \mathrm{sec})\end{array}$ & $\begin{array}{l}\text { Cells cultured in collagen in tissue } \\
\text { culture inserts and exposed to } \\
\text { flow. Followed by chemoattractant } \\
\text { TGF- } \alpha \text { exposure. }\end{array}$ & $\begin{array}{l}\text { Glioma cell lines with low } \\
\text { invasive potential show } \\
\text { decreased chemotaxis after flow } \\
\text { exposure. This is modulated by } \\
\text { MMP activation and expression. }\end{array}$ & Qazi et al ${ }^{47}$ \\
\hline $\begin{array}{l}\text { OVCAR-3 epithelial } \\
\text { ovarian cancer (human) }\end{array}$ & $\begin{array}{l}\text { Shear flow } \\
\left(0.5-1.5 \text { dyne } / \mathrm{cm}^{2}\right)\end{array}$ & $\begin{array}{l}\text { Microfluidic chamber with seeded } \\
\text { cells in two dimensions exposed to } \\
\text { pump-driven shear flow. }\end{array}$ & $\begin{array}{l}\text { Cells elongated and developed } \\
\text { stress fibers in response to flow. }\end{array}$ & $\begin{array}{l}\text { Avraham- } \\
\text { Chakim et al }{ }^{117}\end{array}$ \\
\hline $\begin{array}{l}\text { RT2, C6 rat astrocytoma, } \\
\text { U87 human glioma }\end{array}$ & $\begin{array}{l}\text { Interstitial, continuous } \\
(0.7 \mu \mathrm{m} / \mathrm{sec})\end{array}$ & $\begin{array}{l}\text { Tumor cells in three-dimensional } \\
\text { hyaluronan-collagen matrices. } \\
\text { Hydrostatic pressure and pump } \\
\text { driven flow in tissue culture } \\
\text { inserts, radial flow chambers, } \\
\text { microfluidic devices. }\end{array}$ & $\begin{array}{l}\text { Flow increased glioma invasion. } \\
\text { This was mediated by CXCR4 } \\
\text { activation and possible } \\
\text { autologous chemotaxis. }\end{array}$ & Munson et al ${ }^{46}$ \\
\hline $\begin{array}{l}\text { SNI2L, SNI2C human } \\
\text { renal carcinoma; } \\
\text { MDAMB435S }\end{array}$ & $\begin{array}{l}\text { Interstitial, flow ( } \mathrm{I} \mu \mathrm{m} \\
\text { per second) followed by } \\
\text { static invasion period }\end{array}$ & $\begin{array}{l}\text { Collagen matrices in tissue culture } \\
\text { inserts. A period of flow was } \\
\text { followed by a period of static with } \\
\text { chemoattractant TGF- } \alpha \text { for } 24 \text { or } \\
48 \text { hours. }\end{array}$ & $\begin{array}{l}\text { Flow upregulates MMP-I and } \\
\text { MMP-2; inhibition of adhesion } \\
\text { molecules or degradation of the } \\
\text { glycocalyx inhibited invasion. }\end{array}$ & Qazi et al ${ }^{64}$ \\
\hline $\begin{array}{l}\text { MDAMB23I human } \\
\text { breast carcinoma }\end{array}$ & $\begin{array}{l}\text { Interstitial flow }(4.6 \mu \mathrm{m} \\
\text { per second) }\end{array}$ & $\begin{array}{l}\text { Cells in three-dimensional collagen } \\
\text { matrices with pressure driven flow } \\
\text { across matrix to induce flow. }\end{array}$ & $\begin{array}{l}\text { IF induces reorganization of } \\
\text { focal adhesions in an integrin- } \\
\text { dependent manner. IF induces } \\
\text { paxillin-dependent cell } \\
\text { protrusions. }\end{array}$ & Polacheck et al ${ }^{43}$ \\
\hline
\end{tabular}

Abbreviations: TGF, transforming growth factor; IF, interstitial flow; MMP, matrix metalloproteinase.

are integral to the testing and validation of antitumor therapeutic strategies.

\section{Sensing of interstitial fluid flow}

The mechanism by which a cell senses fluctuations in shear stress and IFs in the extracellular matrix has been better examined in endothelial cells than in cancer cells. ${ }^{59,60}$ Recently, studies in cancer cells have indicated that the glycocalyx may be responsible for mechanosensing of flows. ${ }^{61}$ The glycocalyx consists of a layer of glycoproteins, glycolipids, and proteoglycans that surrounds the cell membrane. This layer is integral to the function of endothelial cells, particularly in the regulation of cell-cell adhesion and immune detection. ${ }^{62}$ Degradation of the glycocalyx layer with glycoprotein-specific enzymes resulted in diminished flow-enhanced invasion in three-dimensional models of cancer. The glycocalyx is important for integrin clustering and binding of cells to their surroundings. ${ }^{63}$ If integrin binding and adhesion to the matrix is blocked, cells lose their mechanosensing properties leading to less aggressive disease. ${ }^{7}$ Reorganization of integrin binding sites due to IFs is a hypothesized mechanism by which cells sense and respond to fluid flow. ${ }^{64}$ Lastly, cancer cells have been shown to have a primary cila that can act as a sensor of the mechanical and 
chemical microenvironment around each cell. ${ }^{65}$ These cilia are vital to tissue development and homeostasis due to their involvement in cell signaling and may have similar signaling pathway effects in cancer. ${ }^{66}$ Regardless of the mechanism, cell sensing of IF is an important attribute of all cells, but in cancer may be a possible pathway to enhance malignancy and resistance to treatment.

\section{Activation of the tumor stroma}

In addition to the direct effects of IF on cancer cells, fluid flow also has effects on the stromal compartment of tumors. Since the tissue stroma frequently encounters and responds to interstitial fluid flow, the primary stromal cells are sensitive to fluctuations in fluid changes. Many of the responses seen in cancer-induced fluid flows are similar to the responses seen in wound healing or infection. ${ }^{67}$

\section{Activation of fibroblasts}

Fibroblasts are sensitive to changes in fluid flows. During progression of cancer, fibroblasts are recruited and transformed to become cancer-associated fibroblasts. ${ }^{68}$ These cells are activated, showing positive expression of cytoskeletal protein alpha-smooth muscle actin, development of stress fibers, and secretion of extracellular matrix proteins and cytokines, such as transforming growth factor beta (TGF- $\beta$ ). Fibroblasts in the absence of cancer cells will respond to high IF rates by becoming myofibroblasts and realigning the extracellular matrix. ${ }^{69}$ When cancer cells and fibroblasts are cultured together, there is an enhancement of cancer cell invasion and fibroblast activation in response to IF. ${ }^{70}$ This response is mediated by TGF- $\beta$. Activation of the tumor stroma, which can include fibroblast activation, can contribute to enhanced metastasis and is hypothesized to mediate much of the downstream immune, angiogenic, and biophysical activation of the tumor microenvironment. ${ }^{71}$

\section{Angiogenesis and lymphangiogenesis}

Interstitial flow in vitro increases angiogenesis and lymphangiogenesis in three-dimensional matrices. ${ }^{62,72,73}$ Shear flows also increase endothelial cell sprouting, adhesion, permeability, and secretion of cytokines. ${ }^{74,75}$ In cancer, it is hypothesized that increases in fluid influx from resident blood vessels will trigger and are necessary for angiogenic processes. Lymphatic endothelial cells exposed to shear or transmural flows undergo a host of changes, including increased immune cell adhesion, cancer cell adhesion, cancer cell transport, and secretion of CCL2, a tumor chemoattractant and proinflammatory chemokine. ${ }^{60,76}$ In multiple ways, blood and lymphatic endothelial cells work in conjunction with interstitial fluid flow to promote cancer. In studies of angiogenesis, we know that blood flow to the cancer area increases before angiogenesis begins via vessel co-option. ${ }^{77} \mathrm{It}$ is possible that other processes, including cytokine secretion and cell adhesion, start long before we see any evidence of new vessel sprouting. In this way, the interaction between the endothelial vessels that perfuse the stroma and the fluid flows that originate from them are cyclically connected to propagate interstitial fluid flows and progression of cancer.

\section{Interstitial flow in the treatment of cancer}

Changes in IF are important for the efficacy of cancer therapy in at times contradictory ways. Although we know that IF can have far-reaching, if not yet fully understood, effects on the progression of cancer, it can also be manipulated in the hope of promoting positive outcomes from treatment. Often changes are incorporated to better distribute therapy to the tumor, without a full understanding of how IF affects cancer.

\section{Transport of therapeutics}

Arguably, the greatest effect that IF can have on cancer therapy and, specifically the failure of cancer therapy, is its effect on the transport of systemically delivered therapeutics. Although it seems that IF should be advantageous in terms of getting therapeutics through the extracellular matrix and to invading cancer cells via convective forces, this is not the case. A high pressure gradient forms at the periphery of the tumor, yielding increased IF. However, there are substantial modeling data suggesting that the majority of the tumor, or tumor bulk, has a uniformly high pressure. ${ }^{11,22}$ This increased pressure neutralizes or reverses the normal pressure differential that exists between blood vessels and healthy tissue, making it more difficult to transport molecules away from the vessel. 4,21,22 This results in a localized distribution of therapy around the entering blood vessels. This effect, combined with the heightened permeability of neoangiogenic blood vessels, has been called the enhanced permeability and retention effect. ${ }^{29,78}$ Depending on the type of therapeutic being delivered and the intended target area of the tumor, this can be either advantageous or not.

In small molecule $(<1 \mathrm{kDa})$ therapy, transport of the therapeutic is diffusion-limited. This means that although the molecule can exit the vessel and often diffuse towards areas of increased fluid flow, these flows do not alter the distribution of the therapy. ${ }^{11}$ For larger therapies, such as immunotherapies 
and nanoparticles, fluid flow can have a substantial effect on the distribution. ${ }^{11}$ However, these therapies are subject to heightened retention near blood vessels, and thus rarely enter the area of high IF flows. Therefore, although IF should yield increases in drug distribution, systemically delivered drugs are limited at the tumor entry point. Thus, many adjuvant therapeutic strategies aim to either bypass this delivery route or alter it in order to re-equilibrate the drainage of the tissue to the advantage of drug delivery. ${ }^{79}$

\section{Changes in IF with therapy}

Although manipulation of fluid flows in cancers has obvious therapeutic implications, standard of care therapies have also been studied to understand the changes in the biophysical microenvironment that occur in patients. Few studies have looked at the effect of therapy on IF velocity. Strategies to target blood vessels, such as antiangiogenic drugs, have been shown to alter the tumor vasculature and decrease interstitial pressure after therapy. ${ }^{80}$ Strategies to increase the temperature of the tissue (such as hyperthermia) appear to reduce interstitial pressure. ${ }^{81}$ Treatment with standard therapies generally appears to reduce interstitial pressure and presumably IF due to the decreased pressure gradient. After radiotherapy in human xenografts, interstitial pressure decreased, ${ }^{82}$ and standard anti-inflammatory therapies such as dimethylformamide and pentoxifylline showed similarly lowered interstitial pressures. ${ }^{25}$ The studies of standard of care therapies and IF or interstitial pressure include patients who are receiving anti-inflammatory agents before any chemotherapy or radiotherapy, so it is difficult to assess the effect of therapeutics on IF.

\section{Manipulation of IF}

\section{as a therapeutic approach}

Changes in IF in the tumor to better resemble that seen in healthy tissue stroma are gaining ground as potential therapeutic strategies. These treatment approaches are mostly experimental, but are seeing benefits in patient cohorts. ${ }^{83}$ The ability to alter the transport of drugs into and through the tumor interstitium is the primary goal in these therapies. That being said, the method and target of the therapies vary and can limit their implementation for particular cancers.

\section{Increasing fluid flow (convection- enhanced delivery)}

Increasing the convective forces in tissues is a technique developed for the delivery of large macromolecules to the central nervous system. ${ }^{84}$ This technique is advantageous for bypassing the blood-brain barrier and yielding a distributed profile of larger drugs. In cancers, a catheter is inserted either intratumorally or intrathecally, and drug is slowly infused over the course of several hours. This method can increase the distribution of drug by an order of magnitude. ${ }^{85}$ This technique was developed over 20 years ago, and since then has been used in a number of clinical trials. Common chemotherapeutics, such as paclitaxel and BCNU, as well as immunotherapies against interleukin-4 and interleukin-13 have been delivered to patients and shown mild success in reducing tumor bulk. ${ }^{86}$

Unfortunately, this technique suffers from difficulties in catheter design and inefficient distribution of drug in the interstitium due to leakage. ${ }^{87}$ The native fluid flow through the tumor tissue, and the potential impact of introducing new fluid flow into this tissue are not well studied. A better understanding of both the fluid flow resulting from direct infusion and the side effects of fluid flow could yield more efficacious implementation of convection-enhanced delivery for brain cancers.

Other cancers benefit from enhanced convection to distribute therapeutics. Besides direct fluid infusion, induction of convection using either heat or ultrasound can lead to higher distribution of drugs throughout tumors. ${ }^{79,81,86-89}$ Hyperthermia-based techniques at low temperatures will induce mild convective fluid flows and lead to redistribution of systemically delivered therapies. ${ }^{88}$ These changes may be due to alterations in vessel permeability and distribution rather than actual changes in fluid patterns in the tissue, but this remains to be determined.

\section{Decreasing fluid flow}

Although there are no identified direct targets to inhibit or reduce IF, techniques to reduce the pressure differential and subsequent increase in fluid flow between the tumor and the surrounding tissue have recently surfaced. The first evidence of benefit over 25 years ago showed that patients receiving angiotensin-converting enzyme inhibitors had an apparent reduction in incidence of cancer. ${ }^{90}$ Use of these vasoconstrictors to increase blood pressure in infiltrating blood vessels is a strategy used to counteract the high pressure of the tumor. Use of angiotensin II receptor antagonists in conjunction with chemotherapy in nanoparticle and free form shows increased efficacy in animal models of cancer. ${ }^{91,92}$ The change in blood influx reduces the overall interstitial pressure of the tumor, which reduces the fluid flow rate at the tumor border, altering the distribution of blood-delivered nutrients and oxygen throughout the tumor. Hence, increases in blood pressure in the tumor could have far-reaching effects on both the study 
and treatment of cancers, and is thought to have a role in "normalizing" the tumor stroma. ${ }^{79}$

A secondary approach to potentially reduce fluid efflux from the tumor is to inhibit drainage via lymphatic vessels..$^{93}$ By inhibiting lymphatic activation, which includes increases in permeability, lymphangiogenesis, and vessel dilation, fluid drainage from the tumor is reduced. ${ }^{94}$ As antibodies against vascular endothelial growth factor receptor-3, a primary receptor involved in lymphatic activation, move to the clinic, further information on the role of lymphatics in tumor normalization will be established.

\section{Potential for therapeutics related to IF}

The ability to manipulate flow through alterations in the biophysical microenvironment or through fluid influx and efflux in the tumor may offer another avenue for treating cancer. However, molecules related to the response of cancer cells to IF could also be used as potential novel therapeutic targets. When examining autologous chemotaxis, several molecules have been identified as modulating flow-enhanced invasion, including chemokine/chemokine receptor pairs. ${ }^{44,46}$ These molecules offer potential targets to minimize the effects of IF on cancer progression. Similar co-expressed chemokine/receptor pairs could be identified in patients to facilitate personalized therapy. Biomechanical sensing is regulated by matrix binding integrins and glycans that form the matrix glycocalyx, and thus offer a potential means to reduce flow responsiveness in cancer cells. Inhibition of $\beta 1$ or $\alpha 3$ integrins or degradation of glycans reduced invasion of cancer cells. ${ }^{7,64}$ Novel therapeutics targeted at integrins or glycans have vast therapeutic potential to mediate flow responsiveness in cancer, and also for modulation of a number of other malignancy-associated behaviors. ${ }^{95}$ Other adhesion molecules and sensing molecules including focal adhesion complex proteins such as focal adhesion kinase, and cytoskeletal assembly molecules are potential therapeutics that directly process fluid flow signals to cancer cells.

Recent studies have looked at the tumor secretome, or constituents of the interstitial fluid in ovarian, ${ }^{96}$ lung, ${ }^{97}$ and breast cancers. ${ }^{98}$ Proteomic screens on lung pleural effusions and ovarian ascites fluids have revealed potential biomarkers in cancer-associated fluid with the potential for therapeutic development. ${ }^{96,97}$ In addition to proteins, exosomes and microRNAs have been identified as playing a role in invasion and metastasis of cancer cells ${ }^{99,100}$ and having interactions with the immune system. ${ }^{101}$ The role of these markers and the potential they hold for diagnosis and therapeutic development are still to be determined. The IF that carries these factors away from the tumors is important to their dispersal and targeting of healthy stromal cells and it is possible that inhibition or manipulation of these extracellular markers may have an impact on the role of IF in tumor progression.

\section{Role of IF in therapeutic resistance: hypotheses}

Although the distribution and delivery of therapeutics is an important aspect of cancer chemoresistance, there are numerous other mechanisms involved in the inefficacy of current therapeutic strategies. Contributors to therapeutic resistance have been extensively reviewed, and include cancer stem cells, ${ }^{102}$ multidrug resistance, ${ }^{103}$ hypoxia, ${ }^{104}$ cancer cell invasion, ${ }^{105}$ and more recently, stromal cells and the extracellular matrix. ${ }^{106-108}$ Aside from cancer cell invasion, there is no evidence that IF affects other mechanisms of therapeutic resistance, although correlations and side effects of other therapies may indicate some role. Noncancerous stem cells, such as adipose-derived and mesenchymal stem cells, respond to interstitial fluid flows by proliferating. Cancer stem cells are found in areas of the tumor stroma near neoangiogenic blood vessels in the perivascular niche, where fluid flows will be high and nutrients enriched in both breast $^{109}$ and brain ${ }^{110}$ cancers. There may be a mechanism of sensing by these cells to home to these niches and remain dedifferentiated, hinted at in shear flow studies indicating $\mathrm{G}_{2} / \mathrm{M}$ arrest. $^{57}$

Expression of multidrug resistance transporters and regulation of extracellularly displayed receptors for anticancer drugs have been found to be regulated by integrin clustering. This has recently been suggested to aid in enhanced chemotherapeutic efficacy in cancers pretreated to alter the extracellular matrix. ${ }^{107,111}$ It is possible that IF may induce cancer cell resistance to chemotherapy through this type of extracellular matrix-mediated pathway. Similarly, hypoxia has been shown to have downstream effects that promote therapeutic resistance in multiple cancer types. ${ }^{112}$ Hypoxic areas of tumors tend to exist in primarily static conditions for long periods of time. Cells in these microclimates of low oxygen express prosurvival proteins and mutate to avoid cell death. Increasing oxygenation to these areas could rescue these cells and make treatment more viable, but the effect of flow in these regions, which is largely static, would be interesting for both a therapeutic and biological understanding of cancer.

Lastly, the far-reaching effect of flow on the tissue stroma may be the most complex and difficult to understand. 
It is undeniable that the tumor microenvironment, including the biophysical and cellular components, is affecting the success of anticancer therapy. ${ }^{1,106,113}$ Early studies indicate that the tumor stroma can affect multidrug resistance, ${ }^{1}$ be altered to create a better therapeutic response, ${ }^{107,114,115}$ and act to initiate and progress cancer via multiple cellular pathways. ${ }^{113}$ Biophysical parameters, such as matrix stiffness, are associated with therapeutic resistance in humans and animal models. This indicates a role of biomechanical factors in modulation of cancer cell behavior. We have seen already that multiple cell types, including fibroblasts and immune cells, in the tissue stroma will respond to IF by activating and altering the microenvironment for the benefit of the cancer cell. ${ }^{116} \mathrm{~A}$ more holistic picture and experimental approach to therapeutic testing, diagnosis, treatment regimen including IF will yield a greater clinical outcome.

\section{Conclusion}

Biophysical effects on tumor progression and response to therapy are beginning to be elucidated. Increased stromal stiffness, interstitial pressure, and IF are apparent in a number of cancers, and increase with progression. Although there is increasing evidence that IF may be significant in the progression of cancer, it is still relatively limited and poorly understood. There is a need for research on the clinical and prognostic significance of changes in fluid flow and its relevance to progression of cancer and its response to therapy. There is a need for further understanding of the multitude of changes that occur when cancer tissue is exposed to the physiological force of fluid flow. There is also a need to understand how and when a cancer cell detects and responds to interstitial fluid and shear stresses beyond the current small number of studies. Although IF is not the single contributor to cancer metastasis and invasion in humans, it is an important part of the tissue stroma, be it healthy or malignant. In order to understand, develop, and model therapeutic delivery and efficacy against cancer, biophysical forces, including interstitial flow, must be taken into account.

\section{Disclosure}

The authors report no conflicts of interest in this work.

\section{References}

1. Correia AL, Bissell MJ. The tumor microenvironment is a dominant force in multidrug resistance. Drug Resist Updat. 2012;15(1-2): 39-49.

2. Hazlehurst LA, Landowski TH, Dalton WS. Role of the tumor microenvironment in mediating de novo resistance to drugs and physiological mediators of cell death. Oncogene. 2003;22(47):7396-7402.
3. Butcher DT, Alliston T, Weaver VM. A tense situation: forcing tumour progression. Nat Rev Cancer. 2009;9(2):108-122.

4. Heldin $\mathrm{CH}$, Rubin K, Pietras K, Ostman A. High interstitial fluid pressure - an obstacle in cancer therapy. Nat Rev Cancer. 2004;4(10): 806-813.

5. Teo CS, Hor Keong Tan W, Lee T, Wang CH. Transient interstitial fluid flow in brain tumors: effect on drug delivery. Chem Eng Sci. 2005;60(17):4803-4821.

6. Paszek MJ, Zahir N, Johnson KR, et al. Tensional homeostasis and the malignant phenotype. Cancer Cell. 2005;8(3):241-254.

7. Levental KR, Yu H, Kass L, et al. Matrix crosslinking forces tumor progression by enhancing integrin signaling. Cell. 2009;139(5):891-906.

8. Yu H, Mouw JK, Weaver VM. Forcing form and function: biomechanical regulation of tumor evolution. Trends Cell Biol. 2011;21(1):47-56.

9. Kumar S, Weaver VM. Mechanics, malignancy, and metastasis: the force journey of a tumor cell. Cancer Metastasis Rev. 2009;28(1-2): $113-127$.

10. BoucherY, Baxter LT, Jain RK. Interstitial pressure gradients in tissueisolated and subcutaneous tumors: implications for therapy. Cancer Res. 1990;50(15):4478-4484.

11. Baxter LT, Jain RK. Transport of fluid and macromolecules in tumors. I. Role of interstitial pressure and convection. Microvasc Res. 1989;37(1):77-104.

12. Boucher Y, Salehi H, Witwer B, Harsh GR, Jain RK. Interstitial fluid pressure in intracranial tumours in patients and in rodents. Br J Cancer. 1997;75(6):829-836.

13. Ariffin AB, Forde PF, Jahangeer S, Arif AB, Soden DM, Hinchion J. Releasing pressure in tumors: what do we know so far and where do we go from here? A review. Cancer Res. 2014;74(10):2655-2662.

14. Netti PA, Baxter LT, Boucher Y, Skalak R, Jain RK. Macro- and microscopic fluid transport in living tissues: application to solid tumors. AIChE J. 1997;43(3):818-834.

15. Butler TP, Grantham FH, Gullino PM. Bulk transfer of fluid in the interstitial compartment of mammary tumors. Cancer Res. 1975; 35(11 Part 1):3084-3088.

16. Chary SR, Jain RK. Direct measurement of interstitial convection and diffusion of albumin in normal and neoplastic tissues by fluorescence photobleaching. Proc Natl Acad Sci U SA. 1989;86(14):5385-5389.

17. PathakAP, Artemov D, Ward BD, Jackson DG, Neeman M, Bhujwalla ZM. Characterizing extravascular fluid transport of macromolecules in the tumor interstitium by MRI. Cancer Res. 2005;64(4):1425-1432.

18. Hompland T, Ellingsen C, Øvrebø KM, Rofstad EK. Interstitial fluid pressure and associated lymph node metastasis revealed in tumors by dynamic contrast-enhanced MRI. Cancer Res. 2012;72(19): 4899-4908.

19. Dafni H, Israely T, Bhujwalla ZM, Benjamin JE, Neeman N. Overexpression of vascular endothelial growth factor 165 drives peritumor interstitial convection and induces lymphatic drain: magnetic resonance imaging, confocal microscopy, and histological tracking of triple-labeled albumin. Cancer Res. 2002;62(22):6731-6739.

20. Baxter LT, Jain RK. Transport of fluid and macromolecules in tumors. IV. A microscopic model of the perivascular distribution. Microvasc Res. 1991;41(2):252-272.

21. Zhao J, Salmon H, Sarntinoranont M. Effect of heterogeneous vasculature on interstitial transport within a solid tumor. Microvasc Res. 2007;73(3):224-236.

22. Welter M, Rieger H. Interstitial fluid flow and drug delivery in vascularized tumors: a computational model. PLoS One. 2013;8(8):e70395.

23. Soltani M, Chen P. Numerical modeling of fluid flow in solid tumors. PLoS One. 2011;6(6):e20344.

24. Gromov P, Gromova I, Olsen CJ, et al. Tumor interstitial fluid - a treasure trove of cancer biomarkers. Biochim Biophys Acta. 2013;1834(11): 2259-2270.

25. Lee I, Boucher Y, Demhartner TJ, Jain RK. Changes in tumour blood flow, oxygenation and interstitial fluid pressure induced by pentoxifylline. Br J Cancer. 1994;69(3):492-496.

26. Folkman J. Angiogenesis. Anпu Rev Med. 2006;57:1-18. 
27. Jain RK. Normalization of tumor vasculature: an emerging concept in antiangiogenic therapy. Science. 2005;307(5706):58-62.

28. Soltani M, Chen P. Numerical modeling of interstitial fluid flow coupled with blood flow through a remodeled solid tumor microvascular network. PLoS One. 2013;8(6):e67025.

29. Stapleton S, Milosevic M, Allen C, et al. A mathematical model of the enhanced permeability and retention effect for liposome transport in solid tumors. PLoS One. 2013;8(12):e81157.

30. Sleeman J, Schmid A, Thiele W. Tumor lymphatics. Semin Cancer Biol. 2009;19(5):285-297.

31. Farnsworth RH, Achen MG, Stacker SA. Lymphatic endothelium: an important interactive surface for malignant cells. Pulm Pharmacol Ther. 2006;19(1):51-60.

32. Hanahan D, Weinberg RA. Hallmarks of cancer: the next generation. Cell. 2011;144(5):646-674.

33. Boucher Y, Jain RK. Microvascular pressure is the principal driving force for interstitial hypertension in solid tumors: implications for vascular collapse. Cancer Res. 1992;52(1):5110-5114.

34. Provenzano PP, Hingorani SR. Hyaluronan, fluid pressure, and stromal resistance in pancreas cancer. Br J Cancer. 2013;108(1):1-8.

35. Lunt SJ, Kalliomaki TM, Brown A, Yang VX, Milosevic M, Hill RP. Interstitial fluid pressure, vascularity and metastasis in ectopic, orthotopic and spontaneous tumours. BMC Cancer. 2008;8:2.

36. Pagès F, Galon J, Dieu-Nosjean MC, Tartour E, Sautès-Fridman C, Fridman WH. Immune infiltration in human tumors: a prognostic factor that should not be ignored. Oncogene. 2010;29(8):1093-1102.

37. Lu P, Weaver VM, Werb $Z$. The extracellular matrix: a dynamic niche in cancer progression. $J$ Cell Biol. 2012;196(4):395-406.

38. Reed RK, Rubin K. Transcapillary exchange: role and importance of the interstitial fluid pressure and the extracellular matrix. Cardiovasc Res. 2010;87(2):211-217.

39. Pathak A, Kumar S. Biophysical regulation of tumor cell invasion: moving beyond matrix stiffness. Integr Biol (Camb). 2011;3(4): 267-278.

40. Kaal EC, Vecht CJ. The management of brain edema in brain tumors. Curr Opin Oncol. 2004;16(6):593-600.

41. Wiig H, Swartz MA. Interstitial fluid and lymph formation and transport: physiological regulation and roles in inflammation and cancer. Physiol Rev. 2012;92(3):1005-1060.

42. Wu M, Swartz M. Modeling tumor microenvironments in vitro. J Biomech Eng. 2014;136(2):1-7.

43. Polacheck WJ, German AE, Mammoto A, Ingber DE, Kamm RD. Mechanotransduction of fluid stresses governs 3D cell migration. Proc Natl Acad Sci U SA. 2014;111(7):2447-2452.

44. Shields JD, Fleury ME, Yong C, Tomei AA, Randolph GJ, Swartz MA. Autologous chemotaxis as a mechanism of tumor cell homing to lymphatics via IF and autocrine CCR7 signaling. Cancer Cell. 2007;11(6):526-538.

45. Haessler U, Teo JCM, Foretay D, Renaud P, Swartz MA. Migration dynamics of breast cancer cells in a tunable 3D interstitial flow chamber. Integr Biol (Camb). 2012;4(4):401-409.

46. Munson JM, Bellamkonda RV, Swartz MA. Interstitial flow in a 3D microenvironment increases glioma invasion by a CXCR4-dependent mechanism. Cancer Res. 2013;73(5):1536-1546.

47. Qazi H, Shi ZD, Tarbell JM. Fluid shear stress regulates the invasive potential of glioma cells via modulation of migratory activity and matrix metalloproteinase expression. PLoS One. 2011; 6(5):e20348.

48. Fleury ME, Boardman KC, Swartz MA. Autologous morphogen gradients by subtle interstitial flow and matrix interactions. Biophys $J$. 2006;91(1):113-121.

49. Tien J, Truslow JG, Nelson CM. Modulation of invasive phenotype by interstitial pressure-driven convection in aggregates of human breast cancer cells. PLoS One. 2012;7(9):e45191.

50. Polacheck WJ, Charest JL, Kamm RD. Interstitial flow influences direction of tumor cell migration through competing mechanisms. Proc Natl Acad Sci U SA. 2011;108(27):11115-11120.
51. Pathak AP, Artemov D, Neeman M, Bhujwalla ZM. Lymph node metastasis in breast cancer xenografts is associated with increased regions of extravascular drain, lymphatic vessel area, and invasive phenotype. Cancer Res. 2006;66(10):5151-5158.

52. Linninger AA, Xenos M, Zhu DC, Somayaji MR, Kondapalli S, Penn RD. Cerebrospinal fluid flow in the normal and hydrocephalic human brain. IEEE Trans Biomed Eng. 2007;54(2):291-302.

53. Harrell MI, Iritani BM, Ruddell A. Tumor-induced sentinel lymph node lymphangiogenesis and increased lymph flow precede melanoma metastasis. Am J Pathol. 2007;170(2):774-786.

54. Geer CP, Grossman SA. Interstitial fluid flow along white matter tracts: a potentially important mechanism for the dissemination of primary brain tumors. J Neurooncol. 1997;32(3):193-201.

55. Young SRL, Riley RG, Kim J, Pavalko FM. Focal adhesion kinase is important for fluid shear stress-induced mechanotransduction in osteoblasts. J Bone Miner Res. 2009;24(3):411-424.

56. Kaiser S, Jossen V, Schirmaier C, et al. Fluid flow and cell proliferation of mesenchymal adipose-derived stem cells in smallscale, stirred, single-use bioreactors. Chemie Ing Tech . 2013;85(1-2): $95-102$.

57. Chang SF, Chang CA, Lee DY, et al. Tumor cell cycle arrest induced by shear stress: roles of integrins and Smad. Proc Natl Acad Sci U SA. 2008;105(10):3927-3932.

58. Demou ZN. Gene expression profiles in 3D tumor analogs indicate compressive strain differentially enhances metastatic potential. Ann Biomed Eng. 2010;38(11):3509-3520.

59. Chien S. Mechanotransduction and endothelial cell homeostasis: the wisdom of the cell. Am J Physiol Heart Circ Physiol. 2007;292(3): H1209-H1224

60. Miteva DO, Rutkowski JM, Dixon JB, Kilarski W, Shields JD, Swartz MA. Transmural flow modulates cell and fluid transport functions of lymphatic endothelium. Circ Res. 2010;106(5): 920-931.

61. Shi ZD, Wang H, Tarbell JM. Heparan sulfate proteoglycans mediate interstitial flow mechanotransduction regulating MMP-13 expression and cell motility via FAK-ERK in 3D collagen. PLoS One. 2011;6(1):e15956.

62. Rutkowski JM, Swartz MA. A driving force for change: interstitial flow as a morphoregulator. Trends Cell Biol. 2007;17(1):44-50.

63. Paszek MJ, Boettiger D, Weaver VM, Hammer DA. Integrin clustering is driven by mechanical resistance from the glycocalyx and the substrate. PLoS Comput Biol. 2009;5(12):e1000604.

64. Qazi H, Palomino R, Shi ZD, Munn LL, Tarbell JM. Cancer cell glycocalyx mediates mechanotransduction and flow-regulated invasion. Integr Biol (Camb). 2013;5(11):1334-1343.

65. Toftgård R. Two sides to cilia in cancer. Nat Med. 2009;15(9): 994-996.

66. Michaud EJ, Yoder BK. The primary cilium in cell signaling and cancer. Cancer Res. 2006;66(13):6463-6467.

67. Schäfer M, Werner S. Cancer as an overhealing wound: an old hypothesis revisited. Nat Rev Mol Cell Biol. 2008;9(8):628-638

68. Ostman A, Augsten M. Cancer-associated fibroblasts and tumor growth - bystanders turning into key players. Curr Opin Genet Dev. 2009;19(1):67-73.

69. Ng CP, Hinz B, Swartz MA. Interstitial fluid flow induces myofibroblast differentiation and collagen alignment in vitro. J Cell Sci. 2005; 118 Pt 20:4731-4739.

70. Shieh AC, Rozansky HA, Hinz B, Swartz MA. Tumor cell invasion is promoted by interstitial flow-induced matrix priming by stromal fibroblasts. Cancer Res. 2011;71(3):790-800.

71. Bhowmick NA, Neilson EG, Moses HL. Stromal fibroblasts in cancer initiation and progression. Nature. 2004;432(7015):332-337.

72. Boardman KC, Swartz MA. Interstitial flow as a guide for lymphangiogenesis. Circ Res. 2003;92(7):801-808.

73. Helm CE, Zisch A, Swartz MA. Engineered blood and lymphatic capillaries in 3-D VEGF-fibrin-collagen matrices with interstitial flow. Biotechnol Bioeng. 2007;96(1):167-176. 
74. Song JW, Munn LL. Fluid forces control endothelial sprouting. Proc Natl Acad Sci U S A. 2011;108(37):15342-15347.

75. Dela Paz NG, Walshe TE, Leach LL, Saint-Geniez M, D'Amore PA. Role of shear-stress-induced VEGF expression in endothelial cell survival. J Cell Sci. 2012;125 Pt 4:831-843.

76. Issa A, Le TX, Shoushtari AN, Shields JD, Swartz MA. Vascular endothelial growth factor-C and C-C chemokine receptor 7 in tumor cell-lymphatic cross-talk promote invasive phenotype. Cancer Res. 2009;69(1):349-357.

77. Nasu R, Kimura H, Akagi K, Murata T, Tanaka Y. Blood flow influences vascular growth during tumour angiogenesis. $\mathrm{Br} J$ Cancer. 1999;79(5-6):780-786.

78. Maeda $\mathrm{H}$. The enhanced permeability and retention (EPR) effect in tumor vasculature: the key role of tumor-selective macromolecular drug targeting. Adv Enzyme Regul. 2001;41:189-207.

79. Jain RK. Normalizing tumor microenvironment to treat cancer: bench to bedside to biomarkers. J Clin Oncol. 2013;31(17):2205-2218.

80. Wu J, Long Q, Xu S, Padhani AR. Study of tumor blood perfusion and its variation due to vascular normalization by anti-angiogenic therapy based on 3D angiogenic microvasculature. J Biomech. 2009;42(6):712-721.

81. Leunig M, Goetz AE, Dellian M, Dell M, Gamarra F, Jain RK. Interstitial fluid pressure in solid tumors following hyperthermia: possible correlation with therapeutic response. Cancer Res. 1992;52(2):487-490.

82. Znati CA, Rosenstein M, Boucher Y, et al. Effect of radiation on interstitial fluid pressure and oxygenation in a human tumor xenograft advances in brief effect of radiation on interstitial fluid pressure and oxygenation in a human. Cancer Res. 1996;56(5):964-968.

83. Hall WA, Rustamzadeh E, Asher AL. Convection-enhanced delivery in clinical trials. Neurosurg Focus. 2003;14(2):e2.

84. Bobo RH, Laske DW, Akbasak A, Morrison PF, Dedrick RL, Oldfield EH. Convection-enhanced delivery of macromolecules in the brain. Proc Natl Acad Sci U S A. 1994;91(6):2076-2080.

85. Saito R, Bringas JR, McKnight TR, et al. Distribution of liposomes into brain and rat brain tumor models by convection-enhanced delivery monitored with magnetic resonance imaging. Cancer Res. 2004;64(7):2572-2579.

86. Vandergrift WA, Patel SJ, Nicholas JS, Varma AK. Convectionenhanced delivery of immunotoxins and radioisotopes for treatment of malignant gliomas. Neurosurg Focus. 2006;20(4):E13.

87. Smith JH, Humphrey JA. Interstitial transport and transvascular fluid exchange during infusion into brain and tumor tissue. Microvasc Res. 2007;73(1):58-73

88. Kong G, Braun RD, Dewhirst MW. Hyperthermia enables tumorspecific nanoparticle delivery: effect of particle size. Cancer Res. 2000;60(16):4440-4405.

89. Frenkel V. Ultrasound mediated delivery of drugs and genes to solid tumors. Adv Drug Deliv Rev. 2008;60(10):1193-1208.

90. Lever AF, Hole DJ, Gillis CR, et al. Do inhibitors of angiotensin-Iconverting enzyme protect against risk of cancer? Lancet. 1998; 352(9123):179-184.

91. Chauhan VP, Martin JD, Liu H, et al. Angiotensin inhibition enhances drug delivery and potentiates chemotherapy by decompressing tumour blood vessels. Nat Commun. 2013;4:2516.

92. Chauhan VP, Stylianopoulos T, Martin JD, et al. Normalization of tumour blood vessels improves the delivery of nanomedicines in a size-dependent manner. Nat Nanotechnol. 2012;7(6):383-388.

93. Tammela T, Zarkada G, Wallgard E, et al. Blocking VEGFR-3 suppresses angiogenic sprouting and vascular network formation. Nature. 2008;454(7204):656-660

94. Das S, Skobe M. Lymphatic vessel activation in cancer. Ann NY Acad Sci. 2008;1131:235-241.

95. Fuster MM, Esko JD. The sweet and sour of cancer: glycans as novel therapeutic targets. Nat Rev Cancer. 2005;5(7):526-542.

96. Kuk C, Kulasingam V, Gunawardana CG, Smith CR, Batruch I, Diamandis EP. Mining the ovarian cancer ascites proteome for potential ovarian cancer biomarkers. Mol Cell Proteomics. 2009;8(4):661-669.
97. Wang Z, Wang C, Huang X, Shen Y, Shen J, Ying K. Differential proteome profiling of pleural effusions from lung cancer and benign inflammatory disease patients. Biochim Biophys Acta. 2012;1824(4):692-700.

98. Celis JE, Gromov P, Cabezón T, et al. Proteomic characterization of the interstitial fluid perfusing the breast tumor microenvironment: a novel resource for biomarker and therapeutic target discovery. Mol Cell Proteomics. 2004;3(4):327-344.

99. Teplyuk NM, Mollenhauer B, Gabriely G, et al. MicroRNAs in cerebrospinal fluid identify glioblastoma and metastatic brain cancers and reflect disease activity. Neuro Oncol. 2012;14(6):689-700.

100. Kosaka N, Iguchi H, Ochiya T. Circulating microRNA in body fluid: a new potential biomarker for cancer diagnosis and prognosis. Cancer Sci. 2010;101(10):2087-2092.

101. Clayton A. Cancer cells use exosomes as tools to manipulate immunity and the microenvironment. Oncoimmunology. 2012;1(1):78-80.

102. Wicha MS, Liu S, Dontu G. Cancer stem cells: an old idea-a paradigm shift. Cancer Res. 2006;66(4):1883-1890.

103. Szakács G, Paterson JK, Ludwig JA, Booth-Genthe C, Gottesman MM. Targeting multidrug resistance in cancer. Nat Rev Drug Discov. 2006;5(3):219-234.

104. Shannon AM, Bouchier-Hayes DJ, Condron CM, Toomey D. Tumour hypoxia, chemotherapeutic resistance and hypoxia-related therapies. Cancer Treat Rev. 2003;29(4):297-307.

105. Lucio-Eterovic AK, Piao Y, de Groot JF. Mediators of glioblastoma resistance and invasion during antivascular endothelial growth factor therapy. Clin Cancer Res. 2009;15(14):4589-4599.

106. Nakasone ES, Askautrud HA, Kees T, et al. Imaging tumor-stroma interactions during chemotherapy reveals contributions of the microenvironment to resistance. Cancer Cell. 2012;21(4):488-503.

107. Miyamoto H, Murakami T, Tsuchida K, Sugino H, Miyake H, Tashiro S. Tumor-stroma interaction of human pancreatic cancer: acquired resistance to anticancer drugs and proliferation regulation is dependent on extracellular matrix proteins. Pancreas. 2004;28(1):38-44.

108. Rintoul RC, Sethi T. Extracellular matrix regulation of drug resistance in small-cell lung cancer. Clin Sci (Lond). 2002;102(4):417-424.

109. Ghajar CM, Peinado H, Mori H, et al. The perivascular niche regulates breast tumour dormancy. Nat Cell Biol. 2013;15(7):807-817.

110. Calabrese C, Poppleton H, Kocak M, et al. A perivascular niche for brain tumor stem cells. Cancer Cell. 2007;11(1):69-82.

111. Baumgartner G, Gomar-Höss C, Sakr L, Ulsperger E, Wogritsch C. The impact of extracellular matrix on the chemoresistance of solid tumors - experimental and clinical results of hyaluronidase as additive to cytostatic chemotherapy. Cancer Lett. 1998;131(1):85-99.

112. Rong Y, Durden DL, Van Meir EG, Brat DJ. "Pseudopalisading" necrosis in glioblastoma: a familiar morphologic feature that links vascular pathology, hypoxia, and angiogenesis. J Neuropathol Exp Neurol. 2006;65(6):529-539.

113. Mueller SN, Germain RN. Stromal cell contributions to the homeostasis and functionality of the immune system. Nat Rev Immunol. 2009;9(9):618-629.

114. Brennen WN, Rosen DM, Wang H, Isaacs JT, Denmeade SR. Targeting carcinoma-associated fibroblasts within the tumor stroma with a fibroblast activation protein-activated prodrug. J Natl Cancer Inst. 2012;104(17):1320-1334.

115. Brennen WN, Isaacs JT, Denmeade SR. Rationale behind targeting fibroblast activation protein-expressing carcinoma-associated fibroblasts as a novel chemotherapeutic strategy. Mol Cancer Ther. 2012;11(2):257-366.

116. Liao D, Luo Y, Markowitz D, Xiang R, Reisfeld RA. Cancer associated fibroblasts promote tumor growth and metastasis by modulating the tumor immune microenvironment in a $4 \mathrm{~T} 1$ murine breast cancer model. PLoS One. 2009;4(11):e7965.

117. Avraham-Chakim L, Elad D, Zaretsky U, Kloog Y, Jaffa A, Grisaru D. Fluid-flow induced wall shear stress and epithelial ovarian cancer peritoneal spreading. PLoS One. 2013;8(4):e60965. 


\section{Publish your work in this journal}

Cancer Management and Research is an international, peer-reviewed open access journal focusing on cancer research and the optimal use of preventative and integrated treatment interventions to achieve improved outcomes, enhanced survival and quality of life for the cancer patient. The journal welcomes original research, clinical \& epidemiological

studies, reviews \& evaluations, guidelines, expert opinion \& commentary, case reports \& extended reports. The manuscript management system is completely online and includes a very quick and fair peerreview system, which is all easy to use. Visit http://www.dovepress.com/ testimonials.php to read real quotes from published authors.

Submit your manuscript here: http://www.dovepress.com/cancer-management-and-research-journal 